\title{
The United Kingdom 2017 Election: Polarization in a Split Issue Space
}

\author{
Cristian Vaccari (Loughborough University, UK) \\ Kaat Smets (Royal Holloway, University of London, UK) \\ Oliver Heath (Royal Holloway, University of London, UK)
}

\begin{abstract}
After decades in which party competition was fought in the centre ground, the 2017 UK General Election witnessed a return to more conflictual politics. In this article, we assess public support for the electoral strategies of the main parties and examine the extent to which the issues the parties campaigned on resonated with their own supporters, as well as with the wider public. Drawing on De Sio and Weber's (2014) issue yield framework, we show that the Conservative campaign - generally considered to be badly run - did not focus on issues that would fully exploit the opportunities for expanding support that were open to the party. Labour, by contrast, played a much better hand. While taking a clear left-wing stance on many policies that were popular with its constituency, the party also skilfully emphasized valence issues that Labour is often seen as more credible on, such as healthcare and education.
\end{abstract}

Version accepted for publication in West European Politics 


\section{Introduction}

The 2017 General Election in the United Kingdom took place against the backdrop of Brexit, one of the most divisive political issues of recent times. After decades in which party competition was fought in the centre ground, this election witnessed a return to more conflictual politics. Yet despite the potential for the election to be a re-run of the 2016 referendum campaign, the issue of Brexit did not form a positional issue in a straightforward way. Voters were presented with a distinct set of policies: Theresa May's vision of a 'hard Brexit', versus Jeremy Corbyn's radical left anti-austerity platform. To a certain extent then the election was fought along two competing value dimensions - which pitted the Conservatives' more authoritarian cultural policies against Labour's left-wing economic policies. Both strategies contained an element of risk and potentially stood to alienate different groups of voters. Perhaps most damagingly, the Conservative strategy risked alienating the socially liberal middle classes that had backed its previous leader David Cameron and supported Remain in the EU Referendum. Meanwhile, the Labour strategy risked alienating the voters that had backed New Labour under Tony Blair. However, both parties gambled that whatever they lost among (more moderate) existing supporters they would be able to compensate by making gains among new or returning supporters.

In this article, we assess public support for the electoral strategies of the main parties and examine the extent to which the issues the parties campaigned on resonated with their own supporters, as well as with the wider public. Was the Conservatives' strategy too narrow? Did the party's focus on Brexit alienate some of its own supporters? And was Labour's decision to fudge Brexit and direct attention elsewhere a successful policy move? Or did the

party's lurch to the left alienate voters? In answering these questions, we draw on De Sio and 
Weber's (2014) issue yield framework. The concept of issue yield takes into account the tension that parties face between trying to appeal to their supporters and attracting new groups of voters. It is thus a summary of the risks and opportunities that different electoral strategies invoke and can be defined as the degree to which an issue allows a party to overcome the conflict between protection and expansion of electoral support (De Sio and Weber 2014: 871).

The challenge that parties face is to identify their most favorable issues, which attract the lowest amount of internal division possible but are widely supported in the electorate at large. This combination of low risk and high opportunity both minimizes the potential for loss of existing support and expands the opportunity to gain new voters (see De Sio 2018 for further discussion). The measure of issue yield that we apply in this paper to Britain for the first time can therefore be seen as a parsimonious means of summarizing the 'traditional' tension that parties face between caterin to their electoral base and appealing to the median voter.

Past research in a variety of different countries indicates that parties do tend to rely on a set of high-yield bridge issues where the party position is almost unanimously supported within the party and also widely shared outside the party (De Sio 2010; De Sio, De Angelis and Emanuele 2016; De Sio and Weber 2014; Weber and De Sio 2016). While each issue presents a different trade-off between risk and opportunity for each party, most major parties tend to be able to rely on at least a small number of high yield issues. The expectation is that parties will disproportionately focus on making these high-yield bridge policies salient in voters' minds during election campaigns in order to gain electoral advantage.

It is this proposition that we investigate with respect to the 2017 UK election. In some respects, the British context represents a challenging test case for issue yield theory, since the election took place in a highly volatile environment where both the risks and opportunities for parties were abundant. Brexit cut across traditional lines of political conflict and introduced a new issue dimension to the electoral arena. The parties wrestled with this new issue dimension in fundamentally different ways. The Conservatives, who had been riding high in the polls ever since the referendum, decided to go all-in on Brexit. They 
gambled that they could convert support for Brexit into a commanding majority, by making serious inroads in the estimated 140 or so Labour-held seats that had given majority support to Leave in the referendum (Hanretty 2016). The party attempted to appeal to such voters by urging them to endorse Prime Minister Theresa May's 'Lancaster House' vision of Brexit, which included leaving the single market and the customs union, as well as ending the free movement of EU nationals. May's brand of 'post-liberal conservatism' was seen by its advocates as different from the more libertarian tradition that had dominated the party in earlier years, and Cameron's more socially liberal conservatism. ${ }^{i}$

By contrast, Labour were largely silent on the issue of Brexit. Although this strategy was widely criticized by party backbenchers and political commentators at the time, in some respects it was a classic heresthetical device. According to Riker's (1986) influential theory, parties who hold unpopular issue positions are expected to de-emphasize the main dimension of conflict and to stress other issues where they enjoy a potential majority position. Having been on the losing side of the referendum, this provided a rationale for Labour to de-emphasize their opposition to Brexit, not least because the issue was also internally divisive - as many Labour MPs represented constituencies that had backed Brexit. Instead, Labour sought to highlight opposition to austerity, a stance that after seven years of Tory-backed cuts was potentially much more popular. Under Jeremy Corbyn then, Labour sought to offer a radical left-wing program that would oppose austerity, tackle poverty, and advance social justice. Labour promised to take water, the Royal Mail, railways and energy back into public ownership, bolster spending on public services, including childcare and the National Health Service, and abolish university tuition fees.

In the event though neither party was able to secure an overall majority (see Heath and Goodwin 2017 for an analysis of the results). For the incumbent Conservative party, a general election that had been called to stamp its authority on Parliament ended in retreat. While the party polled 42.3 per cent of the vote, an increase of 5.4 points on its result in 2015, it won only 317 seats, thirteen fewer than in 2015 when David Cameron had achieved a small but surprising majority, and nine seats short of the 326 it needed for a majority in the House of Commons. Labour meanwhile exceeded all expectations. An election that some feared 
would culminate in a historic loss ended with the party increasing its vote by nearly 10 percentage points to 40 percent, its highest share of the vote since Tony Blair's second landslide in 2001.

Meanwhile, the other parties all suffered set-backs. Most notable was the collapse of the UK Independence Party (UKIP), which saw its share of the national vote drop from almost thirteen per cent to just 1.8 per cent. The Scottish National Party (SNP), the Liberal Democrats, Plaid Cymru and the Greens also recorded declines in their vote share. These results bucked the recent trend towards multipartyism and party system fragmentation and saw a return to two-party politics, with the two main parties receiving their highest combined share of the vote since 1970.

The election was also notable for the volatility in public opinion during the campaign period. Although the traditional view of campaigns is that they make little difference to electoral outcomes and have only a minimal effect on vote choice (see Kalla and Broockman 2018 for a review of past studies), this election witnessed dramatic changes in partisan support during the campaign period. In the week following Theresa May's $18^{\text {th }}$ April announcement of a snap election, the Conservatives enjoyed an average poll lead of over 21 percentage points and seemed to be on course for a crushing majority. However, by the last week of the campaign barely six weeks later, the average Conservative lead in the polls was just 7 percentage points and the final result was even closer, with less than two percentage points separating the parties.ii

This tumultuous pattern raises the question of whether the parties differed in their ability to capture and capitalize their different sources of competitive advantage in a changing landscape. To what extent did the party strategies represent a gamble? Did they appeal to new groups of voters? And did they risk alienating any of the parties' existing supporters?

To answer these questions, we leverage issue yield as a theory of parties' electoral behaviour, and test its implications based on a unique combination of data representing voters' preferences and parties' official campaign communication. In particular, we examine the 
extent to which the parties' official messaging on Twitter during the campaign displayed strategic behaviour-maximizing the available opportunities following the issue yield theory - or followed systemic salience by focussing on those issues salient to the public as a whole. A focus on issue yield implies a targeted electoral strategy which emphasises issues which are both internally popular (among party supporters) and have broad electoral appeal (in the general public) on which parties have a distinct competitive advantage. By contrast, a focus on systemic salience suggests a more broad-brush electoral strategy and indicates that parties focus on issues that are popular overall, regardless of whether they hold a distinct competitive advantage on the issue.

The article proceeds as follows. After discussing our research design, data and measures, we examine the issue preferences of the different party constituencies and examine the ideological divisions within the electorate, focusing specifically on the opportunities that these provided for the main parties. Secondly, we look at the issues that the parties emphasized in their online communications on Twitter and the balance between positional and valence issues in the campaign. Thirdly, we estimate which factors predict the parties' choices to focus on different issues, distinguishing between issue yield and systemic salience. Finally, we draw on our findings to offer some interpretations on the outcome of the UK 2017 general election and highlight some directions for future research.

\section{Research design, data and methods}

To understand the interplay between parties' strategies and electoral incentives, we rely on a mixed-methods approach that integrates two original data sources: a pre-campaign survey conducted on a representative sample of the UK voting-age population and a corpus of all the messages posted on Twitter by the main parties and their leaders during the campaign. The survey data on voters enables us to identify the resources available for party competition, i.e. those issues that offered each party the highest potential for electoral gain. In particular, party constituency data allow us to distinguish between the issues voters thought were important and those where parties had measurable competitive advantages, as identified by their issue yield. In turn, the content analysis of parties' Twitter 
communication during the campaign allows us to assess whether and how parties seized on those competitive advantages when addressing journalists and citizens.

The survey on voters was conducted by Demetra, a commercial research company, between 12 and 31 May 2017, during the campaign and ahead of the election held on 6 June. The survey featured 122 questions, measuring saliency, preferences, and assessments of party credibility on 28 different policy issues (18 positional and 10 valence). ${ }^{. i i}$ The questionnaire also probed respondents' socio-demographic characteristics, general political attitudes, evaluations of the main party leaders, and propensity to vote for them.iv The sample was drawn from an opt-in online panel and was constructed to be representative of the votingage population in the United Kingdom based on gender, age group, geographic area, and education. A total of 1,000 interviews were conducted in the UK, with an additional 100 interviews conducted in Scotland, which we oversampled to ensure we could capture specific patterns in its party competition. The response rate was $37 \%$ in the UK-wide sample and $40 \%$ in the Scottish sample. All subsequent analyses were weighted based on recall of the vote in the 2015 General Election. ${ }^{v}$

To study party communication, we collected all the messages published by the main national parties and their leaders on Twitter during the election campaign. Twitter is a useful source of data to study parties' official communication. First, it is publicly accessible so that the data can be freely collected, which ensures consistency and reproducibility of our results. Second, Twitter is widely adopted in the United Kingdom, as 25 percent of the population uses it and only Facebook, among social media platforms, is more popular as a source of news (Reuters Institute for the Study of Journalism, 2017). Third, Twitter is heavily used by journalists, who have come to treat it like an additional reporting "beat" (Broesma \& Graham 2012), and this makes it appealing for politicians as a broadcasting tool for political public relations (Parmelee 2014; Kreiss 2016; Verweij, 2012).

While other sources of data, such as party manifestos, could also be used to measure parties' policy positions, the advantage of using Twitter data is that it provides a more dynamic summary of what parties actually talk about during the campaign. Because Twitter 
communication is continuous, it allows us to focus on the issues that matter as they develop and to examine how the parties responded to unexpected crises, such as the terrorist attacks that took place during the campaign after the manifestos were published (see note iv). Another advantage of this choice is that it allows comparison across the six countries included in this special issue, as discussed in the other articles, based on the same methodology.

To collect data on parties' communication, we queried the Twitter Search API, which provides access to the last 3,200 tweets posted by any account.vi We identified the official Twitter accounts of the six main parties (Conservatives, Labour, Liberal Democrats, United Kingdom Independence Party, Greens, and Scottish National Party) and their leaders (Theresa May, Jeremy Corbyn, Tim Farron, Paul Nuttal, Caroline Lucas and Jonathan Bartley who stood jointly as Green party leaders, and Nicola Sturgeon).vii Together, these six parties combined for $96.2 \%$ of all the votes cast in the election. We retained all the tweets that had been posted in the final four weeks of the campaign - from 10 May until 7 June, the day before the vote. To ensure our data only included official party messages that were intended to reach their whole audience, we filtered the tweets posted during this period to exclude retweets, @replies to tweets, tweets containing only links, and duplicate tweets. This resulted in a total of 3,725 tweets, all of which we coded manually to identify the primary issue they focused on based on the list of 10 valence issues and 18 positional issues we measured in the survey questionnaire. viii

Two of the authors performed all the codingix, following a procedure established for the whole comparative project to ensure consistency across countries. To achieve reliability in the coding, each of the two coders independently coded a first sample of 378 tweets $110 \%$ of the total), randomly chosen from the whole corpus. In this first round, inter-coder agreement was 75\%, and Krippendorff's alpha was 0.67 (Krippendorff, 1980). The coders then discussed and reached an agreement on each of the tweets on which they had disagreed. They subsequently performed another round of independent coding of an additional random sample of 200 tweets. This yielded much higher inter-coder agreement (85\%), and Krippendorff's alpha (0.81) was above the threshold of 0.80 which is normally required to 
consider coding as reliable. ${ }^{x}$ The coders discussed again all the tweets which they had coded differently and agreed on their classification. Having achieved high levels of reliability and a strong common understanding on how to code all the issues, each of the coders then independently coded half of the remaining tweets. ${ }^{x i}$ All the coded tweets were then consolidated into the final dataset of party communication. We then integrated the survey dataset and the Twitter content analysis dataset to compare and contrast voters' preferences and parties' communication.

\section{Issue priorities and party constituencies}

We start the analysis by examining the public resources available for party competition, i.e. those issues that offer each party the highest potential for electoral gain. Table 1 shows the issue yield for each party constituency and information on the component parts that go into the construction of the index (within-party support, overall support, and credibility of the party to handle the issue). For the purposes of comparison, all valence issues are assumed to be supported by $100 \%$ of the public and party supporters.

The issue yield summary index is calculated according to a nonlinear expression that combines support for different issues within the party base and the electorate at large, weighted by party credibility, thus allowing a generalization to valence issues (see De Sio and Weber 2014 and De Sio and Weber's article in this special issue for more details). The index can be summarized as:

issue yield $=\frac{(\mathrm{f}-\mathrm{ip}) \text { intcred }}{\mathrm{p}(1-\mathrm{p})}+\frac{(\mathrm{i}-\mathrm{p}) \mathrm{cred}}{1-\mathrm{p}}$

Where:

$\mathrm{i}$ = proportion of electorate supporting a policy;

$\mathrm{p}=$ proportion of electorate supporting a party;

$\mathrm{f}=$ proportion of electorate supporting both;

cred $=$ party credibility on the goal in the electorate at large 
intcred $=$ party credibility on the goal within the party base

High values on the yield index indicate that the issue in question is both internally popular among party supporters and has broad electoral appeal in the general public. In sum, these are issues on which parties have a distinct competitive advantage and because issue yield is a party-specific measure the issues that are considered most strategic vary from party to party. Low values on the yield index indicate the issue in question appeals either only to the parties' base without attracting broader support, or is popular in the electorate at large but risks alienating the parties' own supporters.

For example, for the Conservative Party, the positional issues of "leaving the European Union", "Investing more public money to build affordable homes", and "Banning the Islamic veil in public places" yielded drastically different potential benefits in 2017. According to our survey, $77 \%$ of the Conservative supporters agreed that Britain should leave the EU, as did a majority of the general population (55\%). Moreover, $29 \%$ of the population considered the Conservatives as a credible party to achieve these goals. This resulted in a high issue yield (see Table 1 below for the top 5 issue yield configurations for the Conservative and Labour Party) because the issue had broad support both in the party base and in the general population, and the party was seen as reasonably credible in implementing the policy. By contrast, when it comes to investing in affordable homes, the general public was quite in favour of this policy (72\%) but the party base was more tepid about it (66\%) and the party's credibility among the public was low (17\%). Hence, the issue had low yield for the Conservatives because it risked alienating one-third of their supporters and, even if it was popular among the rest of the electorate, the party was not seen as particularly credible in dealing with the issue. Finally, the issue of banning the Islamic veil registered substantial support among Conservative supporters (77\%) but much lower support among the general population (64\%), so focusing on this issue may have pleased the base but could have disappointed a large sector of the electorate, especially considering the low credibility the party enjoyed om the issue (17\%). Notice, however, that even though the mismatch between the preferences of party supporters and the general public is similar for the housing and Islamic veil issues, and the party's credibility is estimated as the same on both issues, the 
value of issue yield is higher for banning the Islamic veil (0.21) than for building affordable housing (0.10). This is because the formula places greater weight on the preferences of party supporters, who are more likely to remain loyal, than to those of the voters at large, many of whom are loyal to other parties and may thus not be amenable to change their preferences even if a party shifts its positions to appeal to them.

\section{Table 1 about here}

Whatever party sorting occurred before the start of the election campaign, by the time the survey was conducted (i.e. a month after the election was called) the two main parties had quite distinctive issue-based sources of competitive advantage (see Table 1). For the Conservatives, the issues with the highest yield were a mix of valence issues to do with leadership, security and the economy, and authoritarian positional issues to do with Brexit and defence, which were all areas where the party enjoyed a competitive advantage over its rivals. For a right wing party though it is noticeable that there are no positional right wing economic issues on this list. Indeed, the five most popular positional issues for the party were all cultural issues. Restricting welfare for immigrants (which, arguably, can be considered as partly cultural and partly economic), banning the Islamic veil in public places, leaving the European Union, maintaining Trident, and requiring foreigners to fully adapt to British culture were all supported by over three-quarters of Conservative party identifiers. The positional issues that were particularly popular among the party faithful, and where the party enjoyed a competitive advantage, were all culturally rather than economically conservative.

By contrast, for Labour the issues with the highest yield were a mix of valence issues to do with the NHSxii and pensions, and left wing positional issues to do with increasing the minimum wage, scrapping tuition fees and banning zero hours contracts (that is, contracts where the employer is not obliged to provide a minimum number of working hours). Indeed, the five most popular positional issues for the party were all left-wing economic issues increasing the minimum wage, scrapping tuition fees, banning zero hours contracts, 
nationalizing railways, reducing income differences, and raising taxes to spend more on public services were all supported by over three-quarters of Labour party identifiers.

Thus, the issues where the parties had the most to gain were clearly structured along two orthogonal value dimensions. Rather than ideological boundaries being blurred, the election presented a straightforward conflict between an economically left wing constituency and a socially conservative constituency. Ideology was therefore meaningful, yet competition was not between two poles on the same axis, but between positions on two different dimensions: culture versus economics.

\section{Party communication on Twitter during the campaign}

We next turn to the electoral strategies pursued by the parties during the course of the campaign. What did parties tweet about? Did they emphasize low risk valence issues? Or did they also emphasize positional issues where they enjoyed a competitive advantage? To what extent did parties' Twitter communication display strategic behaviour - maximizing the available opportunities following the issue yield theory?

To this end, Figure 1 plots the percentage of tweets posted by each of the parties (and their leaders) focusing on the 28 issues we coded against the yield of that issue for each party. xiii White squares represent valence issues, while black triangles represent positional issues. Appendix D shows the percentages of tweets that each party and its leaders posted on all issues.

\section{Figure 1 about here}

Looking at the issue each party tweeted the most about reveals the different strategies they employed: leaving the EU for the Conservatives $33.7 \%$ of the total tweets by the party and its leader), improving the NHS for Labour (18,4\%), keeping Britain in the EU for the LiberalDemocrats (25.5\%), raising taxes and spending more on public services for the SNP (17.9\%), 
protecting the environment for the Greens (21.4\%), and leaving the EU for UKIP (9.2\%, on par with taxes and spending).

Across all parties, the two most mentioned issues were positional (staying or leaving the EU with $15.9 \%$ of all tweets and cutting/raising taxes to spend less/more on health and social services with $11.5 \%$ of all tweets; see Appendix D). These were key themes particularly for the two main parties, but while Conservatives and Labour posted identical percentages of tweets on the tax and spend issue (10.7\%), the difference could not be starker in terms of Brexit, which was the subject of $33.7 \%$ of Conservative tweets and only $0.9 \%$ of Labour tweets. When we aggregate tweets across all parties, the next seven issues the parties tweeted the most about were all valence: improving the NHS, providing leadership for the country, boosting economic growth, improving schools, protecting the environment, protecting pensions, and protecting the UK from terrorist attacks.

Interestingly, among the ten issues with the highest yields, five concern the Conservative party (listed in Table 1). This shows that the Conservative leadership's calculus that calling a snap election would benefit the incumbent party had some basis in reality, as Conservatives seemed to hold most of the relevant issue-based competitive advantages. By contrast, among the ten issues with the highest yield, only two involved the Labour party-increasing the minimum wage and scraping or reducing tuition fees, both positional issues, ranked third and eighth overall.

The trend lines in Figure 1 suggests that there is a positive bivariate relationship between parties' electoral incentives to address different issues (measured by issue yield) and parties' communication strategies (measured by the percentage of tweets they posted on each issue). While our analysis will examine this relationship more systematically in the next section, the fact that the trend line for valence issues is steeper than the one for positional issues suggests that parties were keener to seize electoral advantages based on management of noncontroversial priorities than those rooted in conflicts between clear alternatives. Overall, the correlation between issue yield and percentage of tweets posted is nearly twice as strong for 
valence issues $(0.4509, p=0.0055, N=60)$ than for positional issues $(0.2656, p=0.0003, N$ $=108)$.

However, the balance between valence and positional issues varied substantially by party in terms of both electoral incentives and campaign communication. To illustrate this, Figure 2 compares the average yield of positional and valence issues with the percentage of tweets each party posted about those two types of issues.

\section{Figure 2 about here}

From the left panel of the figure, we can see that in terms of electoral incentives, the Conservatives and Labour had very similar average yields on positional issues, but the incumbent party had the edge on valence issues. However, from the right panel of Figure 2 we can see that the Conservatives focused on positional issues (by and large Brexit) more than any other party (apart from the Lib-Dems, who emphasized the opposite position on the same issue) and nearly twice as much as Labour. By contrast, even though Labour under Corbyn rediscovered left wing policies that were previously considered as radical, the party's official communication on Twitter mostly focused on valence issues. Four of the top five issues in the party's and its leader's tweets were valence (improving the NHS, protecting pensions, improving the quality of schools, and fighting crime) while only one was positional (raising taxes to spend more on health and social services). Clearly, there was a connection between the valence goals of bolstering public services and the positional issue of raising taxes to marshal the necessary resources. Still, cumulatively, most of Labour's messaging was aimed at reminding voters the party was committed to those widely agreed societal goals rather than taking more controversial stances on the means by which this purpose would be achieved.

Another important difference between the two main parties' communication is that the Conservatives were noticeably more focused (and repetitive) than Labour. While only three issues-leaving the EU, providing leadership for the country, and boosting economic growth-make up more than $60 \%$ of the Conservatives' and May's tweets, it takes as many 
as seven issues to make up the same percentage among the tweets Labour and Corbyn posted. While the Conservatives bet massively, and rationally, on three of the four issues that promised to yield the highest electoral returns for them (see Table 1), their laser-like focus on those themes meant they could not capitalize on other issues where they also enjoyed large competitive advantages. As we saw in Table 1, the Tories had the largest issue yield with respect to protecting the country from terrorist attacks, but only $4.6 \%$ of the tweets they posted during the campaign focused on this topic.xiv Mrs May's party also stood to benefit from talking about maintaining the UK's nuclear weapons and fighting crime, but Conservatives only talked about those issues in $2.6 \%$ and $2.1 \%$ of their tweets.

\section{Strategic party behaviour and issue yield}

Finally, to more systematically gauge how the parties responded to different strategic incentives and opportunities to emphasize particular issues, we conducted a tobit regression analysis to assess whether the share of a party's tweets on a given topic is best predicted by issue yield or by systemic issue salience.

If parties focus on issue yield, this implies a targeted electoral strategy, which prioritizes issues which are both internally popular (among party supporters) and have broad electoral appeal (in the general public), and on which the parties have a distinct competitive advantage. Because issue yield is a party-specific measure, the issues that generate the highest yield are different across different parties. By contrast, a focus on systemic salience suggests a more broad-brush electoral strategy and indicates that parties address issues that are popular overall (regardless of whether they hold a distinct competitive advantage on the issue). Because systemic salience refers to the electorate at large the issues that are most salient are the same for each party.

The unit of analysis is parties*issues ( 6 parties*28 issues results in a sample size of 168). The dependent variable in the analyses presented below is the relative emphasis a party puts on a given issue, measured as a proportion of tweets on a given topic out of the total number of 
tweets by that party (empirical range $0-0.337$ ). The (theoretical) range of the independent variables is $0-1$ for systemic salience and -1 to +1 for issue yield. This implies that in a hypothetical example where both variables have the same coefficient size, this corresponds to a twice as large effect for issue yield due to the larger empirical range of the variable. In order to facilitate interpretation of the effect sizes we will also present $\mathrm{x}$-standardized coefficients, whereby both variables are scaled to range between $0-1$.

Table 2 shows the results for all parties grouped together. The first two models are bivariate and report the impact of issue yield and systemic salience respectively on the party share of tweets. Both variables are positive and significant predictors. However, as noted above, a balanced electoral strategy indicates that parties emphasize both types of issues simultaneously. This is the case for UK parties. In the third and combined model ${ }^{\mathrm{xv}}$, both issue yield $(\mathrm{b}=.13, p<.001)$ and systemic salience $(\mathrm{b}=.27, p<.001)$ are positive and significant predictors of the share of party tweets. The effect size of both variables is roughly the same, as the coefficient for issue yield is approximately half the size of the coefficient for systemic salience while the former's range is twice as large as the latter's. This is confirmed when looking at the $\mathrm{x}$-standardized coefficients (issue yield beta $=.26$, systemic salience beta $=.27$ ). It thus appears that UK parties, on average, focus on strategic issues and system-wide salient issues in roughly equal measure in their Twitter communication. ${ }^{\mathrm{xvi}}$

In terms of model fit, the variance explained of the issue yield model is .090 and that explained by the systemic salience model is $\mathbf{. 1 9 4}$. In the combined model the variance explained is .247 , which is a notable gain that suggests that the two variables combined substantially improve our understanding of the parties' strategies and that, overall, parties employ both considerations in deciding which issues to discuss in the campaign.

\section{Table 2 about here}

Does the mix between these two approaches vary across parties? There are many reasons to think that it might. For example, mainstream parties may focus more on systemic salience because they have greater power to shape what issues the electorate at large cares about, 
while niche parties, who have much less agenda-setting power, may only focus on those issues that define and distinguish them. There may also be differences in emphasis according to the size of the party, incumbency status, and whether or not parties are office-seeking, vote-seeking, or policy-seeking. Although we cannot test these propositions directly with the data we have, we can assess whether any of the parties adopt markedly different approaches and whether some were more strategically oriented than others.

To examine these issues, we added interaction terms identifying each party to both the issue yield and systemic salience variables. Figure 3 shows the marginal effects of issue yield and systemic salience for each of the six main UK political parties (see Appendix B for the full model from which these marginal effects are derived). The marginal effects plot confirms that issue yield and systemic salience are statistically significant predictors of the share of party tweets for all six parties. However, the extent to which targeted issue yield and generic issue salience predict parties' communication differs between parties. For Labour and the Greens, the marginal effects of issue yield are much larger than for systemic salience. These parties, therefore, focussed more on issues on which they had a competitive advantage. For the Liberal Democrats the marginal effects of systemic salience and issue yield are roughly equivalent, indicating a balanced electoral strategy. By contrast, for the Conservatives, UKIP and the SNP the marginal effects of systemic salience are larger than for issue yield. These parties thus emphasized issues the general public cared about, though not necessarily ones on which they enjoyed a competitive advantage.

\section{Figure 3 about here}

De Sio and Weber's (this issue) more comprehensive analysis suggests that the more a party's communication strategy is geared to issue yield considerations, the better the party tends to perform in an election. To a certain extent our findings are consistent with this argument, although only partially so. The two parties whose communication was least centred on issues that had the highest yield and that focussed more on systemic salience both had bad results and were probably the two biggest losers of the election. UKIP's share of the vote plummeted by over 10 percentage points and the party lost its only seat. The SNP also 
performed badly and saw its vote share fall by 13 percentage points in Scotland, which resulted in a loss of 21 seats. But there is less clear-cut evidence to suggest that parties who focussed primarily on issue yield tended to fare better. Although Labour increased its share of the vote by 9.5 percentage points, the party's largest single advance since Clement Atlee led them to victory in 1945, the Green Party saw its share of the vote decline from 3.8 to 1.6 percent of the national vote. The two parties with balanced electoral strategies also had mixed fortunes. The Liberal Democrats saw their vote share fall slightly from the already disastrous 2015 result, but still managed to pick up two seats, whereas the Conservatives saw their vote share increase by 5 percentage points but lost 13 seats and with them their majority in parliament.

\section{Conclusion}

During the last two decades, UK political parties have become ideologically more similarmore centrist and more liberal-and elections have therefore been fought on valence issues, with handling of the economy particularly important. The 2017 election disrupted many of these patterns. Under Jeremy Corbyn's leadership, the Labour party moved abruptly to the left and called for a fairer redistribution of economic growth, to tackle poverty, advance social justice and oppose austerity. The Conservatives, on the other hand, embraced a much more socially conservative position to capitalize on the outcome of the Brexit referendum and attract former UKIP voters.

In the aftermath of the election the Conservatives were widely derided for running a botched campaign, and Theresa May's two Chief Advisors carried the can and immediately resigned. Although it is clear that the campaign was badly executed, was it also badly designed from a strategic point of view? The results from our analysis indicate that to a certain extent it was. The Tory campaign did not fully exploit the opportunities for expanding support that were open to them. This is indicated by the relatively low marginal effect of issue yield on the party's communication (Figure 3). In terms of the issues where they enjoyed a competitive advantage, the Tories went overboard in their rhetoric on "getting on with the job" of Brexit (which risked alienating their more moderate supporters who were uneasy about it) and 
"strong and stable leadership" (which, repeated ad nauseam during the campaign, ended up opening the door for mockery of May's rigid communication style). Although these issues were advantageous for the Conservatives, they received much higher prominence than they deserved and ended up crowding out other potential sources of electoral gain. Issues on which the Conservatives could have capitalised, to do with defence and security, barely featured in their online messaging. This is surprising given the increased salience of these issues following terror attacks during the campaign and the fact that they were widely seen as problematic for Labour under Corbyn - who had to repeatedly defend himself against allegations that he had previously associated with terrorist organisations in the Middle East, and as an avowed pacifist struggled to answer questions on whether he would ever use nuclear deterrents. These missed opportunities may have ended up hurting the Conservatives. Although May's party managed to increase its vote share on the last election, they haemorrhaged public support during the campaign and, instead of gaining a stronger mandate from the public, found themselves short of the parliamentary majority they had and hoped to expand.

By contrast, Labour played a much better hand and made the most of the cards they were dealt. There is a clear left-wing anti-austerity constituency in Britain, and rather than being out of touch with the public mood, as many New Labour grandees feared, Labour's message under Corbyn resonated both with party supporters and the wider public. By offering its supporters policies they strongly agreed with, Labour also thwarted the electoral threat potentially inherent in its vague position on Brexit, shifting the conversation to a terrain where the two-third majority of its Remain-voting supporters and the sizable one-third minority of its Leave-voting supporters could converge even as both groups may have had reservations on the party's position on the referendum and its implementation. While taking a clear left wing stand on many policies that were popular with its constituency, Labour also skilfully emphasized valence issues that the party is generally seen as more credible on, such as healthcare and education.

Based on the issue yield framework, our analysis has revealed that Labour's campaign mostly played to its electoral strengths, while the Conservatives' campaign did so only 
partially. However, Labour still lost the election, albeit by a much narrower margin than precampaign opinion polls predicted, and the Conservatives still emerged as the largest parliamentary party, though deprived of the thin majority they had gained two years before. There are thus limits to the extent that issue yield can explain election results. But as decades of research show, voting behaviour is affected by a variety of long-term and short-term factors, and campaigns are only one among many reasons why elections turn out the way they do.

Although the traditional view of campaigns is that they make little difference to electoral outcomes and have only a minimal effect on vote choice (Kalla and Broockman 2018), the 2017 General Election in the United Kingdom was notable for the dramatic changes that occurred in party support during the campaign. How much this had to do with the nature of the campaign strategies is open to question. But what does seem clear is that issue yield highlights some reasons why Labour did much better than anyone could have predicted and some of the missed opportunities the Conservatives could have seized. 
Table 1 - Top 5 Issue Yield Configurations for the Conservative and Labour Party

$\begin{array}{cccc}\text { Issue } & \text { Within } & \text { Overall } & \text { Party } \\ \text { Yield } & \text { party } & \text { Support } & \text { Credibility } \\ & \text { support } & & \\ & & \end{array}$

Conservatives

\begin{tabular}{lcccc}
\hline 1) Protect the UK from terrorist attacks (v) & 0.55 & - & - & $55 \%$ \\
2) Leave the European Union (auth) & 0.48 & $77 \%$ & $55 \%$ & $29 \%$ \\
3) Provide leadership for the country (v) & 0.46 & - & - & $46 \%$ \\
4) Boost economic growth (v) & 0.46 & - & - & $46 \%$ \\
5) Maintain Britain's nuclear weapons & 0.44 & $74 \%$ & $60 \%$ & $37 \%$ \\
(Trident) (auth) & & & & \\
\hline Labour & & & & $47 \%$ \\
\hline 1) Increase the minimum wage (left) & 0.50 & $88 \%$ & $81 \%$ & $34 \%$ \\
2) Scrap or reduce the cost of university & 0.45 & $85 \%$ & $70 \%$ & $44 \%$ \\
tuition fees (left) & & & & $41 \%$ \\
3) Improve the NHS (v) & 0.44 & - & - & $39 \%$ \\
4) Ban zero hours contracts for workers (left) & 0.39 & $81 \%$ & $80 \%$ & - \\
5) Protect pensions (v) & 0.39 & - & - & \\
\hline
\end{tabular}


Table 2 - Predicting the share of party tweets

\begin{tabular}{lccc}
\hline & $\begin{array}{c}\text { Issue yield } \\
\text { Model }\end{array}$ & $\begin{array}{c}\text { Systemic salience } \\
\text { model }\end{array}$ & $\begin{array}{c}\text { Combined } \\
\text { Model }\end{array}$ \\
\hline Issue yield & $0.17^{* * *}$ & & $0.13^{* * *}$ \\
& $(0.05)$ & & $(0.05)$ \\
& {$[0.34]$} & $0.29^{* * *}$ & $0.27^{* * *}$ \\
Systemic salience & & $(0.05)$ & $(0.04)$ \\
& & {$[0.29]$} & {$[0.27]$} \\
Constant & & $-0.18^{* * *}$ & $-0.19^{* * *}$ \\
& -0.02 & $(0.04)$ & $(0.03)$ \\
\hline Sigma & $(0.01)$ & $0.07^{* * *}$ & $0.07^{* * *}$ \\
& $0.07^{* * *}$ & $(0.00)$ & $(0.00)$ \\
\hline$N$ & $(0.01)$ & 168 & 168 \\
AIC & 168 & -194.90 & -202.57 \\
BIC & -169.28 & -185.53 & -190.08 \\
VarExp & -159.91 & 0.194 & 0.247 \\
\hline
\end{tabular}

Note: $\mathrm{b}$ coefficients from tobit analysis with standard errors in parentheses and $\mathrm{x}$ standardized coefficients in brackets; ${ }^{*} \mathrm{p}<0.05,{ }^{* *} \mathrm{p}<0.01,{ }^{* * *} \mathrm{p}<0.001$ 
Figure 1 - Valence and positional issues in parties' tweets (percentage of total issuefocused tweets by party) and voters' assessments (issue yield)

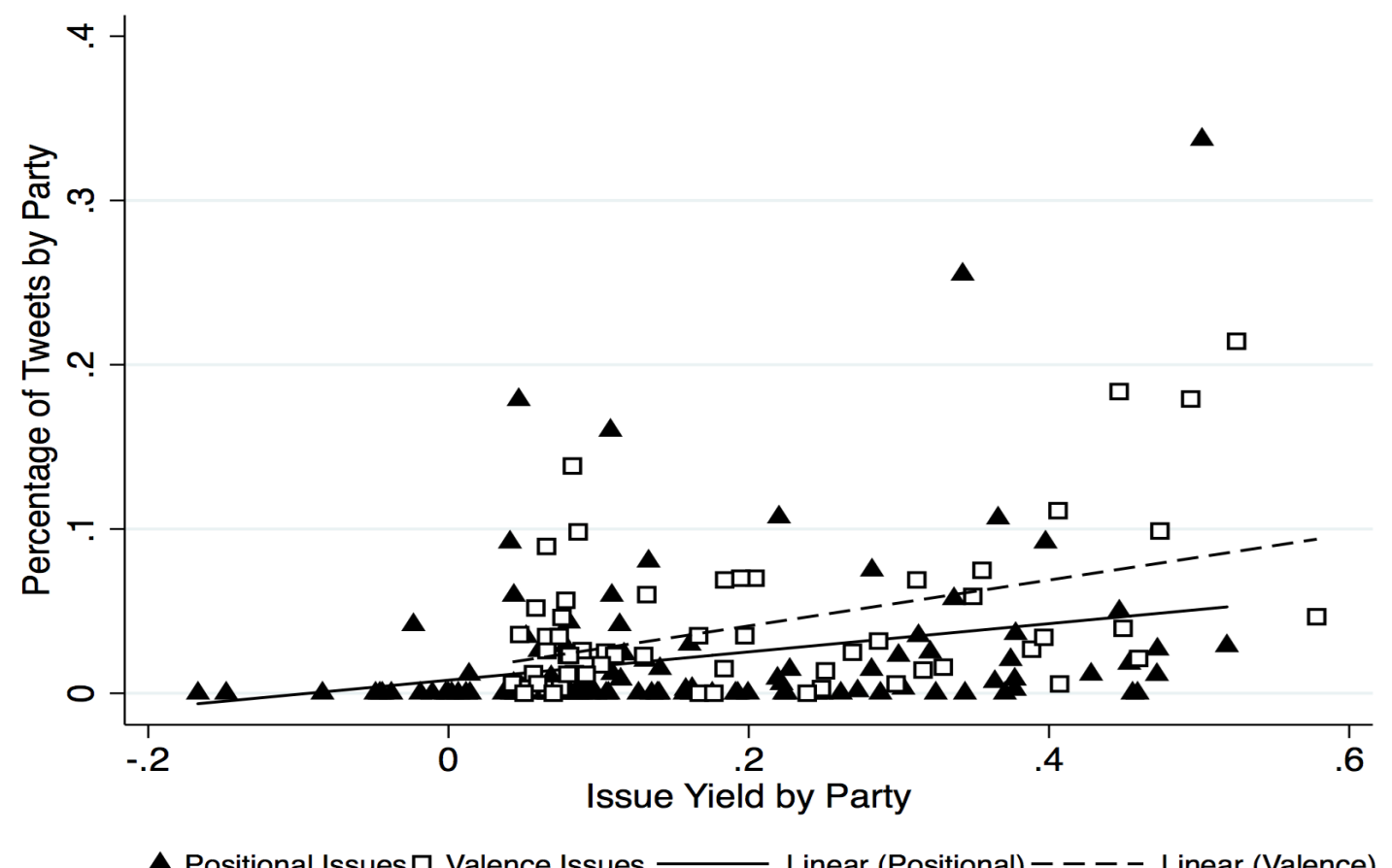


Figure 2 - Voters' Preferences (average issue yield) and Parties' Tweets (percentage of total issue-related tweets) on Position and Valence Issues, by Party
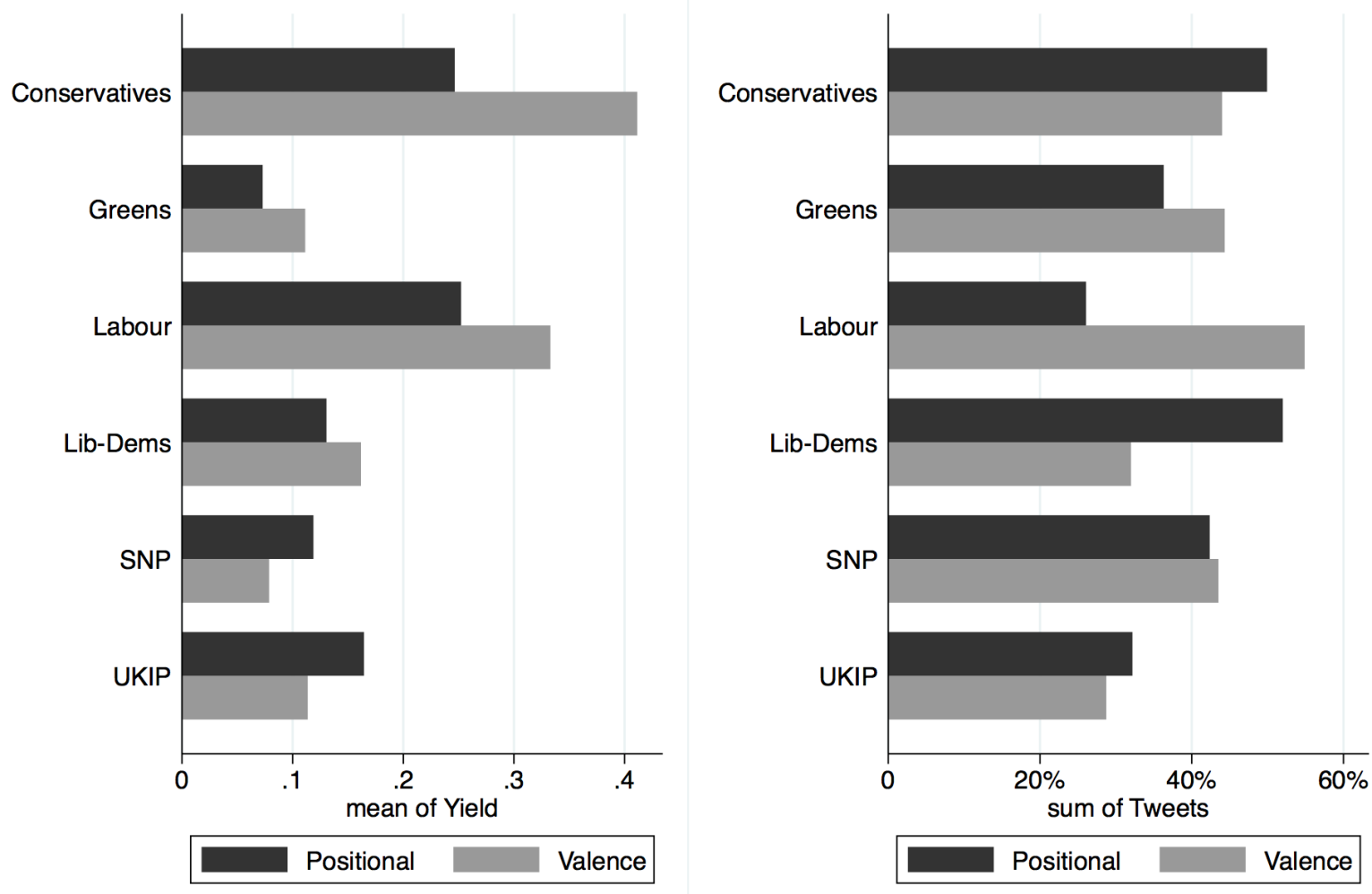

Note: the sum of the percentages of positional and valence tweets in the right panel does not add to $100 \%$ because the percentages were calculated on the basis of all the tweets posted by parties, including those that were about issues we did not classify and those that had no issue content. 
Figure 3 - Marginal effects of issue yield and systemic salience

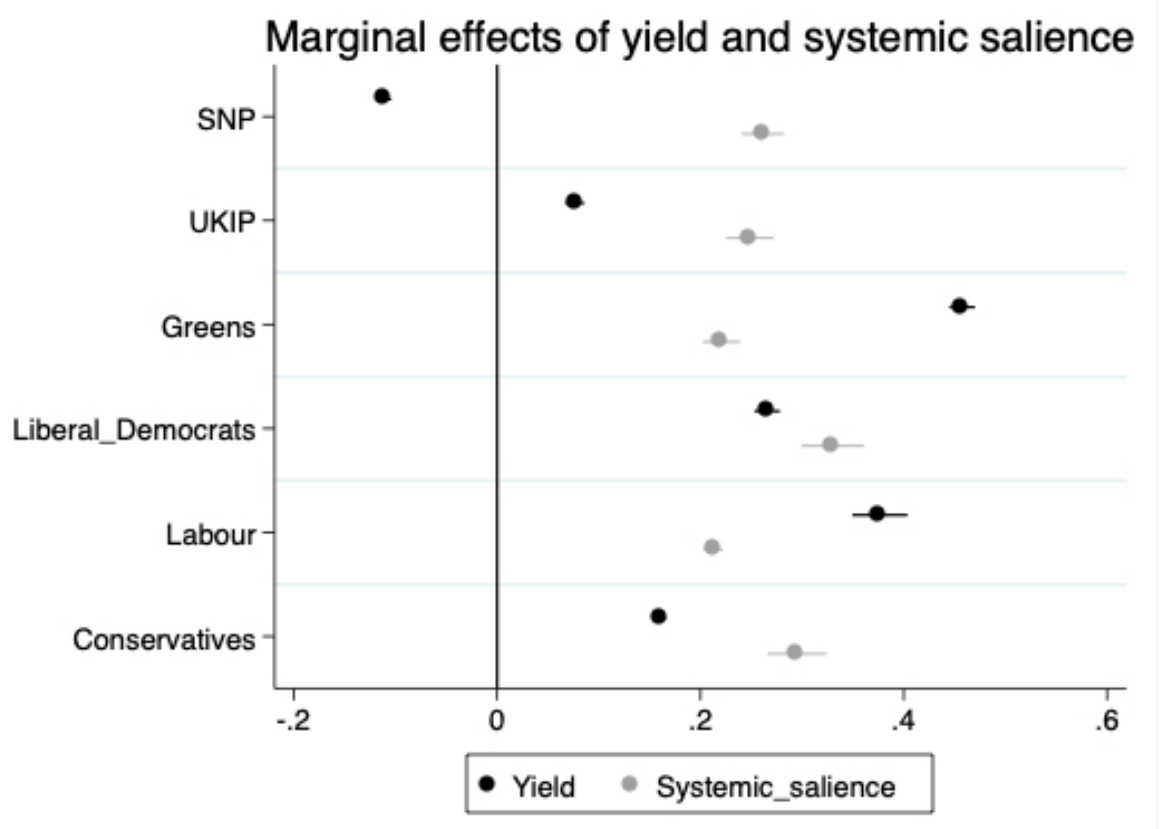

Note: Estimates are based on the coefficients from Model 2 in Appendix B (Table B1). 


\section{References}

Baker, R., Blumberg, S. J., Brick, J. M., Couper, M. P., Courtright, M., Dennis, J. M., ... \& Zahs, D. (2010). Research synthesis AAPOR report on online panels. Public Opinion Quarterly, 74(4), 711-781.

Bartle, J., Dellepiane-Avellaneda, S. and Stimson, J. (2011). The moving centre: Preferences for government activity in Britain, 1950-2005. British Journal of Political Science, 41(2), pp.259-285.

Broersma, M., \& Graham, T. (2012). Social media as beat: Tweets as a news source during the 2010 British and Dutch elections. Journalism Practice, 6(3), 403-419.

Clarke, H., Sanders, D., Stewart, M., Whiteley, P. 2004. Political choice in Britain. Oxford University Press.

Clarke, H., Sanders, D., Stewart, M., Whiteley, P. 2009. Performance Politics and the British Voter. Cambridge University Press.

De Sio, L., De Angelis, A., \& Emanuele, V. (2017). Issue Yield and Party Strategy in Multiparty Competition. Comparative Political Studies, doi: 10.1177/0010414017730082.

De Sio, L. and Weber, T., 2014. Issue yield: A model of party strategy in multidimensional space. American Political Science Review, 108(4), pp.870-885.

Evans, G., Heath, A. and Lalljee, M., 1996. Measuring left-right and libertarian-authoritarian values in the British electorate. British Journal of Sociology, pp.93-112.

Goodwin, M.J. and Heath, O., 2016a. The 2016 referendum, Brexit and the left behind: an aggregate-level analysis of the result. The Political Quarterly, 87(3), pp.323-332.

Goodwin, M.J. and Heath, O., 2016b. Brexit vote explained: poverty, low skills, and lack of opportunity. Joseph Rowntree Foundation.

Goodwin, M., and Heath, O. (2017). 'UK 2017 General Election Examined: Income, Poverty and Brexit.' Joseph Rowntree Foundation. 
Green, J. (2007). When voters and parties agree: Valence issues and party competition. Political Studies, 55(3), 629-655.

Hanretty, C., 2017. Areal interpolation and the UK's referendum on EU membership. Journal of Elections, Public Opinion and Parties, 27(4), pp.466-483.

Heath, O. and Goodwin, M., 2017. The 2017 General Election, Brexit and the Return to TwoParty Politics: An Aggregate-Level Analysis of the Result. The Political Quarterly, 88(3), pp.345-358.

Kalla, J.L. and Broockman, D.E., 2018. The minimal persuasive effects of campaign contact in general elections: Evidence from 49 field experiments. American Political Science Review, 112(1), pp.148-166.

Kreiss, D. (2016). Seizing the moment: The presidential campaigns' use of Twitter during the 2012 electoral cycle. New Media \& Society, 18(8), 1473-1490.

Krippendorff, K. (1980). Reliability. John Wiley \& Sons, Inc.

McCombs, M. E., \& Shaw, D. L. (1972). The agenda-setting function of mass media. Public opinion quarterly, 36(2), 176-187.

Parmelee, J. H. (2014). The agenda-building function of political tweets. New Media \& Society, 16(3), 434-450.

Pasek, J. (2015). When will nonprobability surveys mirror probability surveys? Considering types of inference and weighting strategies as criteria for correspondence. International Journal of Public Opinion Research, 28(2), 269-291.

Reuters Institute for the Study of Journalism (2017) Reuters Digital News Report - United Kingdom. Available at: http://www.digitalnewsreport.org/survey/2017/unitedkingdom-2017

Riker, W.H., 1986. The art of political manipulation (Vol. 587). Yale University Press.

Sanders, D., Clarke, H., Stewart, M. and Whiteley, P., 2001. The economy and voting. Parliamentary Affairs, 54(4), pp.789-802. 
Sanders, D., Clarke, H. D., Stewart, M. C., \& Whiteley, P. (2007). Does mode matter for modeling political choice? Evidence from the 2005 British Election Study. Political Analysis, 15(3), 257-285.

Scotto, T., Sanders, D., and Reifler, J. (2018). 'The consequential nationalist-globalist policy divide in contemporary Britain: some initial analyses' Journal of Elections, Public Opinion and Parties 28 (1): 38-58.

Tilley, J. R. (2005). Research Note: Libertarian-authoritarian Value Change in Britain, 19742001. Political Studies, 53(2), 442-453.

Verweij, P. (2012). Twitter links between politicians and journalists. Journalism Practice, 6(5-6), 680-691.

Whiteley, P., Stewart, M.C., Sanders, D. and Clarke, H.D., 2005. The issue agenda and voting in 2005. Parlamentary Affairs, 58(4), pp.802-817. 


\section{APPENDIX B - PARTY SPECIFIC ANALYSIS}

Table B1 - Predicting the share of party tweets (party specific)

\begin{tabular}{|c|c|c|}
\hline & Model 1 & Model 2 \\
\hline \multirow[t]{3}{*}{ Issue yield } & $0.13^{* * *}$ & $-0.11^{* * *}$ \\
\hline & $(0.05)$ & $(0.00)$ \\
\hline & {$[0.26]$} & {$[-0.22]$} \\
\hline \multirow[t]{3}{*}{ Systemic salience } & $0.27^{* * *}$ & $0.26^{* * *}$ \\
\hline & $(0.04)$ & $(0.01)$ \\
\hline & {$[0.27]$} & {$[0.26]$} \\
\hline \multirow[t]{3}{*}{ UKIP } & & $-0.03^{* * *}$ \\
\hline & & $(0.00)$ \\
\hline & & {$[-0.22]$} \\
\hline \multirow[t]{3}{*}{ Greens } & & $-0.03^{* * *}$ \\
\hline & & $(0.00)$ \\
\hline & & {$[-0.60]$} \\
\hline \multirow[t]{3}{*}{ Liberal Democrats } & & $-0.12^{* * *}$ \\
\hline & & $(0.01)$ \\
\hline & & {$[-0.49]$} \\
\hline \multirow[t]{3}{*}{ Labour } & & $-0.09^{* * *}$ \\
\hline & & $(0.00)$ \\
\hline & & {$[-0.58]$} \\
\hline \multirow[t]{3}{*}{ Conservatives } & & $-0.09 * * *$ \\
\hline & & $(0.00)$ \\
\hline & & {$[-0.37]$} \\
\hline \multirow[t]{3}{*}{ UKIP*Issue yield } & & $0.19^{* * *}$ \\
\hline & & $(0.00)$ \\
\hline & & {$[0.38]$} \\
\hline Greens*Issue yield & & $0.57^{* * *}$ \\
\hline
\end{tabular}


$(0.00)$

[1.14]

LibDems *Issue yield

$0.38^{* * *}$

$(0.00)$

[0.76]

Labour *Issue yield

$0.49^{* * *}$

(0.01)

[0.98]

Conservatives*Issue yield

$0.27^{* * *}$

(0.00)

[0.55]

UKIP *Systemic salience

$-0.01^{* * *}$

$(0.00)$

[-0.01]

Greens*Systemic salience

$-0.04^{* * *}$

$(0.00)$

[-0.04]

LibDems *Systemic salience

$0.07^{* * *}$

$(0.00)$

[0.07]

Labour *Systemic salience

$-0.05^{* * *}$

(0.01)

[-0.05]

Conservatives*Systemic salience

$0.03^{* * *}$

[0.03]

\begin{tabular}{lcc} 
Constant & $-0.19^{* * *}$ & $-0.14^{* * *}$ \\
& $(0.03)$ & $(0.01)$ \\
\hline Sigma & $0.07^{* * *}$ & $0.06^{* * *}$ \\
& $(0.00)$ & $(0.01)$ \\
\hline
\end{tabular}




\begin{tabular}{lcc}
\hline$N$ & 168 & 168 \\
AIC & -202.57 & -231.00 \\
BIC & -190.08 & -227.88 \\
VarExp & 0.247 & 0.354 \\
\hline
\end{tabular}

Note: $\mathrm{b}$ coefficients from tobit analysis with standard errors in parentheses and $\mathrm{x}$ standardized coefficients in brackets; reference category: SNP; ${ }^{*} \mathrm{p}<0.05,{ }^{* *} \mathrm{p}<0.01,{ }^{* * *}$ $\mathrm{p}<0.001$ 


\section{APPENDIX C - ANALYSES WITHOUT REGIONAL PARTIES}

Table C1 - Predicting the share of party tweets - excluding SNP

\begin{tabular}{lccc}
\hline & $\begin{array}{c}\text { Issue yield } \\
\text { Model }\end{array}$ & $\begin{array}{c}\text { Systemic salience } \\
\text { model }\end{array}$ & $\begin{array}{c}\text { Combined } \\
\text { Model }\end{array}$ \\
\hline Issue yield & $0.21^{* * *}$ & & $0.16^{* * *}$ \\
& $(0.04)$ & & $0.03)$ \\
& {$[0.42]$} & $0.33]$ \\
Systemic salience & & $0.30^{* * *}$ & $0.27^{* * *}$ \\
& & $(0.06)$ & $(0.04)$ \\
Constant & & {$[0.30]$} & {$[0.27]$} \\
& -0.24 & $-0.19^{* * *}$ & $-0.20^{* * *}$ \\
Sigma & $(0.02)$ & $(0.04)$ & $(0.04)$ \\
& $0.07^{* * *}$ & $0.07^{* * *}$ & $0.07^{* * *}$ \\
\hline$N$ & $(0.01)$ & $(0.00)$ & $(0.00)$ \\
AIC & 140 & 140 & 140 \\
BIC & -130.69 & -145.60 & -156.40 \\
VarExp & -121.86 & -136.85 & -144.63 \\
\hline
\end{tabular}

Note: $\mathrm{b}$ coefficients from tobit analysis with standard errors in parentheses and $\mathrm{x}$ standardized coefficients in brackets; ${ }^{*} \mathrm{p}<0.05,{ }^{* *} \mathrm{p}<0.01,{ }^{* * *} \mathrm{p}<0.001$ 
Figure C2 - Marginal effects of issue yield and systemic salience- excluding SNP

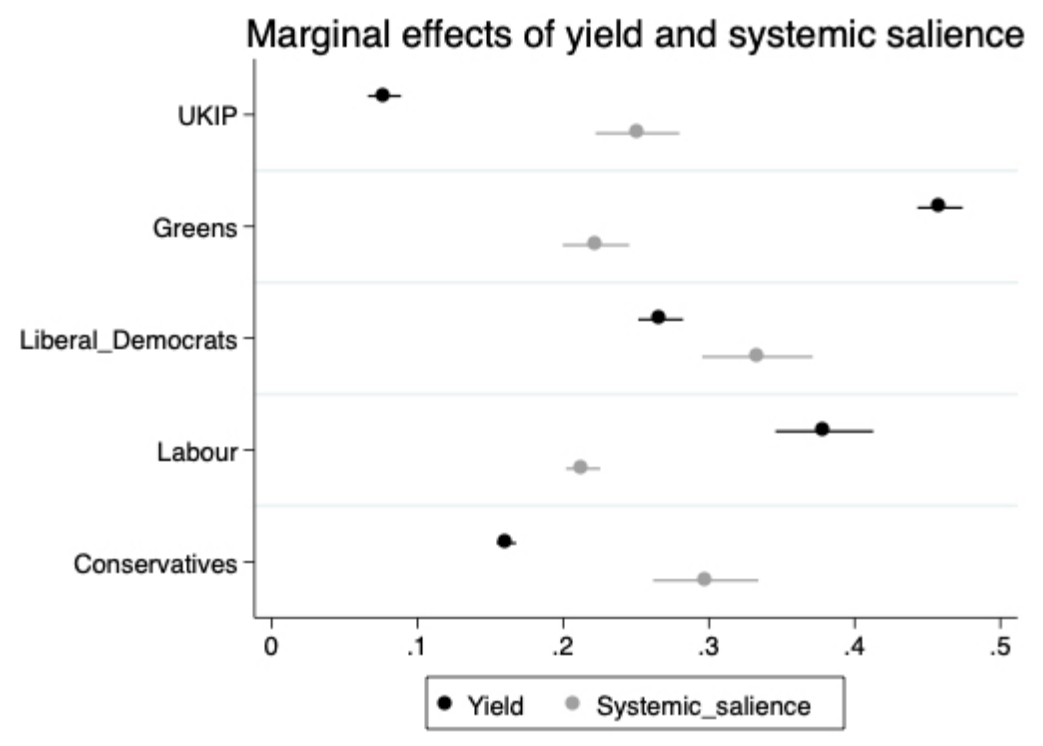

Note: Estimates are based on the coefficients from Model 2 in Table C3.

Table C3 - Predicting the share of party tweets (party specific) - excluding SNP

\begin{tabular}{lcc}
\hline & Model 1 & Model 2 \\
\hline Issue yield & $0.16^{* * *}$ & $0.08^{* * *}$ \\
& {$[0.03)$} & {$[0.01)$} \\
& {$[0.33]$} & {$[0.15]$} \\
Systemic salience & $0.27^{* * *}$ & $0.25^{* * *}$ \\
& $(0.04)$ & {$[0.01)$} \\
& {$[0.27]$} & {$[0.25]$} \\
Greens & & $-0.00^{* * *}$ \\
& & {$[0.00)$} \\
& & {$[-0.39]$} \\
Liberal Democrats & & $-0.09^{* * *}$
\end{tabular}


(0.00)

[-0.28]

Labour

$-0.07^{* * *}$

[-0.37]

Conservatives

$-0.07^{* * *}$

(0.00)

[-0.15]

Greens*Issue yield

$0.38^{* * *}$

$(0.00)$

[0.76]

LibDems *Issue yield

$0.19^{* * *}$

(0.00)

[0.38]

Labour *Issue yield

$0.30^{* * *}$

(0.01)

[0.60]

Conservatives*Issue yield

$0.08^{* * *}$

$(0.00)$

[0.17]

Greens*Systemic salience

$-0.03^{* * *}$

$(0.00)$

[-0.03]

LibDems *Systemic salience

$0.08^{* * *}$

[0.08]

Labour *Systemic salience

$-0.04^{* * *}$

(0.01)

[-0.04]

Conservatives*Systemic salience

$0.05^{* * *}$ 
$(0.00)$

[0.05]

\begin{tabular}{lcc} 
Constant & $-0.20^{* * *}$ & $-0.17^{* * *}$ \\
& $(0.04)$ & $(0.01)$ \\
\hline Sigma & $0.07^{* * *}$ & $0.06^{* * *}$ \\
& $(0.00)$ & $(0.01)$ \\
\hline$N$ & 140 & 140 \\
AIC & -156.40 & -180.01 \\
BIC & -144.63 & -177.07 \\
VarExp & 0.278 & 0.377 \\
\hline
\end{tabular}

Note: $\mathrm{b}$ coefficients from tobit analysis with standard errors in parentheses and $\mathrm{x}$ standardized coefficients in brackets; reference category: UKIP; ${ }^{*} \mathrm{p}<0.05,{ }^{* *} \mathrm{p}<0.01,{ }^{* * *}$ $\mathrm{p}<0.001$ 
APPENDIX D - CONTENT OF THE PARTIES' TWEETS

\begin{tabular}{|c|c|c|c|c|c|c|c|}
\hline & Cons & Lab & L-D & SNP & Green & UKIP & All \\
\hline Remain in/leave the European Union (p) & $33.7 \%$ & $0.9 \%$ & $25.5 \%$ & $7.5 \%$ & $3.0 \%$ & $9.2 \%$ & $15.9 \%$ \\
\hline Cut/raise taxes and spend less/more on social services (p) & $10.7 \%$ & $10.7 \%$ & $16.0 \%$ & $17.9 \%$ & $6.0 \%$ & $9.2 \%$ & $11.6 \%$ \\
\hline Improve the NHS (v) & $1.4 \%$ & $18.4 \%$ & $7.0 \%$ & $13.8 \%$ & $9.8 \%$ & $2.3 \%$ & $8.9 \%$ \\
\hline Provide leadership for the country (v) & $17.9 \%$ & $2.5 \%$ & $2.5 \%$ & $1.2 \%$ & $3.6 \%$ & $3.4 \%$ & $7.6 \%$ \\
\hline Boost economic growth $(\mathrm{v})$ & $9.9 \%$ & $3.2 \%$ & $6.0 \%$ & $5.2 \%$ & $1.2 \%$ & $2.3 \%$ & $5.7 \%$ \\
\hline Improve the quality of schools (v) & $2.7 \%$ & $7.5 \%$ & $7.0 \%$ & $8.9 \%$ & $5.7 \%$ & $3.4 \%$ & $5.6 \%$ \\
\hline Protect the environment (v) & $0.3 \%$ & $1.4 \%$ & $3.5 \%$ & $2.6 \%$ & $21.4 \%$ & $0.0 \%$ & $4.5 \%$ \\
\hline Protect pensions (v) & $0.6 \%$ & $11.1 \%$ & $0.0 \%$ & $4.6 \%$ & $0.3 \%$ & $0.0 \%$ & $3.3 \%$ \\
\hline Protect the UK from terrorist attacks (v) & $4.7 \%$ & $1.6 \%$ & $3.5 \%$ & $1.7 \%$ & $1.2 \%$ & $6.9 \%$ & $3.0 \%$ \\
\hline Reduce/maintain the cost of university tuition fees (p) & $0.0 \%$ & $5.0 \%$ & $2.0 \%$ & $2.9 \%$ & $6.0 \%$ & $1.1 \%$ & $2.7 \%$ \\
\hline Fight crime and keep communities safe (v) & $2.1 \%$ & $5.9 \%$ & $1.5 \%$ & $2.3 \%$ & $0.3 \%$ & $2.3 \%$ & $2.6 \%$ \\
\hline End/allow freedom of movement of people from the EU into Britain (p) & $0.8 \%$ & $0.0 \%$ & $3.5 \%$ & $1.4 \%$ & $8.0 \%$ & $0.0 \%$ & $2.1 \%$ \\
\hline Control immigration (v) & $3.9 \%$ & $0.0 \%$ & $1.0 \%$ & $0.6 \%$ & $0.6 \%$ & $6.9 \%$ & $1.9 \%$ \\
\hline Reduce/do not reduce income differences (p) & $0.0 \%$ & $2.0 \%$ & $0.0 \%$ & $4.3 \%$ & $4.2 \%$ & $0.0 \%$ & $1.8 \%$ \\
\hline Invest more public money/rely on the private sector to build affordable homes (p) & $0.8 \%$ & $3.6 \%$ & $1.5 \%$ & $0.6 \%$ & $2.4 \%$ & $0.0 \%$ & $1.7 \%$ \\
\hline Maintain/dismantle nuclear weapons (p) & $2.7 \%$ & $0.0 \%$ & $0.0 \%$ & $0.6 \%$ & $4.2 \%$ & $0.0 \%$ & $1.7 \%$ \\
\hline Reduce unemployment (v) & $0.6 \%$ & $3.4 \%$ & $0.0 \%$ & $2.6 \%$ & $0.3 \%$ & $1.1 \%$ & $1.4 \%$ \\
\hline Allow/do not allow Scotland to vote in another referendum on independence (p) & $0.7 \%$ & $0.5 \%$ & $1.0 \%$ & $2.9 \%$ & $0.0 \%$ & $0.0 \%$ & $0.9 \%$ \\
\hline Increase/do not increase the minimum wage $(\mathrm{p})$ & $0.3 \%$ & $1.1 \%$ & $0.0 \%$ & $2.6 \%$ & $0.3 \%$ & $0.0 \%$ & $0.8 \%$ \\
\hline Remain in/leave the European Single Market (p) & $0.0 \%$ & $0.0 \%$ & $2.5 \%$ & $1.4 \%$ & $1.2 \%$ & $2.3 \%$ & $0.8 \%$ \\
\hline Nationalize/do not nationalize railways (p) & $0.0 \%$ & $1.8 \%$ & $0.0 \%$ & $0.3 \%$ & $0.3 \%$ & $0.0 \%$ & $0.5 \%$ \\
\hline Require foreigners to adapt to British culture/Allow them to preserve their culture (p) & $0.1 \%$ & $0.0 \%$ & $0.0 \%$ & $0.0 \%$ & $0.0 \%$ & $5.7 \%$ & $0.3 \%$ \\
\hline Expand/limit the provision of grammar schools (p) & $0.0 \%$ & $0.0 \%$ & $0.0 \%$ & $0.0 \%$ & $0.6 \%$ & $3.4 \%$ & $0.2 \%$ \\
\hline Allow/prohibit fracking to produce more oil and gas (p) & $0.0 \%$ & $0.2 \%$ & $0.0 \%$ & $0.0 \%$ & $0.3 \%$ & $0.0 \%$ & $0.1 \%$ \\
\hline Ban/maintain zero hours contracts for workers (p) & $0.0 \%$ & $0.2 \%$ & $0.0 \%$ & $0.0 \%$ & $0.0 \%$ & $0.0 \%$ & $0.0 \%$ \\
\hline Ban/allow the Islamic veil in public spaces (p) & $0.0 \%$ & $0.0 \%$ & $0.0 \%$ & $0.0 \%$ & $0.0 \%$ & $1.1 \%$ & $0.0 \%$ \\
\hline Keep/repeal the law that allows gay marriages (p) & $0.0 \%$ & $0.0 \%$ & $0.0 \%$ & $0.0 \%$ & $0.0 \%$ & $0.0 \%$ & $0.0 \%$ \\
\hline Restrict/maintain levels of access to welfare benefits for immigrants (p) & $0.0 \%$ & $0.0 \%$ & $0.0 \%$ & $0.0 \%$ & $0.0 \%$ & $0.0 \%$ & $0.0 \%$ \\
\hline Other issues & $6.1 \%$ & $19.0 \%$ & $16.0 \%$ & $14.1 \%$ & $19.3 \%$ & $39.1 \%$ & $14.5 \%$ \\
\hline$N$ & 709 & 441 & 200 & 347 & 336 & 87 & 2120 \\
\hline
\end{tabular}

Note: the table shows the percentage of tweets that each party and its leaders posted on each issue against the total tweets with some issue content by that party and leaders. ( $p)$ = positional issues; $(v)=$ valence issues. 


\section{Notes}

i Nick Timothy, 'If we want to win, Tories cannot be free-market fundamentalists', The Daily Telegraph, August 10 2017. Available at: https://www.telegraph.co.uk/news/2017/08/10/nick-timothy-want-win-toriescannot-free-market-fundamentalists/

ii See http://ukpollingreport.co.uk/voting-intention-2

iii This distinction has been the subject of intense academic debate in the past few years. In particular, Green (2007) argued that valence issues are defined more by the fact that parties' positions converge on them than by their inherent content and characteristics. While the issue yield framework introduced in this special issue takes these considerations into account and offers a conceptual and empirical apparatus that goes beyond the distinction between positional and valence issues, we adopt the distinction in this paragraph because it still captures some relevant dynamics of party competition in the British 2017 General Election.

iv Although surveys administered to online opt-in panels suffer from several biases (e.g. Baker et al. 2010), studies comparing in-person and internet surveys (Sanders et al. 2007) as well as probability and nonprobability samples (Pasek 2015) suggest that online panel-based samples tend to produce accurate estimates of the relationship between politically relevant variables.

v Part of the survey fieldwork was conducted in the aftermath of a terrorist bombing that took place at Manchester Arena on 22 May, following a concert by the singer Ariana Grande. Twenty-three people, including the attacker, were killed and more than five hundred were injured. Ten of the dead were less than twenty years old, the youngest being an eight-year old girl. Two other terrorist attacks occurred in London before and after our survey fieldwork was conducted. On 22 March, a terrorist drove a car into pedestrians near the Palace of Westminster, where the British Parliament meets, and injured more than fifty people, five of whom died. On 3 June, three attackers first drove a van into pedestrians in London Bridge, then stabbed people in nearby bars and restaurants, killing eight and wounding forty-eight.

vi In theory, Twitter users can "protect" their accounts, which means that their messages are visible only to users they follow, and thus are not publicly accessible. For obvious reasons, no parties and party leaders choose to take advantage of this opportunity.

vii The account usernames at the time we collected the data were as follows: @Conservatives, @UKLabour, @LibDems @UKIP, @TheGreenParty, @theSNP (parties) and @theresa_may, @jeremycorbyn, @timfarron, @paulnuttallukip, @CarolineLucas, @jon_bartley, @NicolaSturgeon (leaders).

viii The breakdown of total tweets by account is as follows (percentage of the total in parentheses): Conservatives 769 (20.64\%), Labour 510 (13.69\%), Liberal Democrats 334 (8.97\%), UKIP 257 (6.90\%), Greens 414 (11.11\%), SNP 529 (14.20\%), Theresa May 52 (1.40\%), Jeremy Corbyn 364 (9.77\%), Tim Farron 64 (1.72\%), Paul Nuttal 70 (1.88\%), Caroline Lucas 143 (3.84\%), Jon Bartley 121 (3.25\%), Nicola Sturgeon 98 (2.63\%). Overall, parties posted substantially more messages $(2,813$, or $75.52 \%$ of the total) than leaders $(912$, or $24.48 \%$ ). No party leader tweeted more than his/her party's official account did. In our analyses, we aggregated the tweets posted by each party and their leader(s). The number of messages was reasonably balanced across parties, though slightly skewed in favour of the two largest ones. The breakdown by party is as follows (percentages in parenthesis): Conservatives 821 (22.04\%), Labour 874 (23.46\%), Liberal Democrats 398 (10.68\%), UKIP 327 (8.78\%), Greens 678 (18.20\%), SNP 627 (16.83\%).

ix For each of the 28 issues we aimed to code, we identified a small number of keywords (between two and five per issue) that we expected would be found in tweets focusing on that issue. We then used software to automatically parse all the tweets and identify those that contained at least one of the keywords. We then read each of the tweets containing the keywords and decided how it should be coded. In the process, we decided to exclude some keywords that generated inaccurate or ambiguous attributions, while adding other keywords that appeared in tweets relevant to specific issues more systematically than we had anticipated. Once this iterative process had been completed, we manually coded all tweets. We started from the tweets that contained one of the keywords we had identified as potentially indicative of the presence of one of our 28 issues, assessing each of them separately and independently of the suggested automated classification. We then moved on to the tweets that did not contain any of the keywords and coded each of them as well. When a tweet touched upon two issues, we assigned it to the issue we considered to be prevalent and, when both issues seemed equally prominent, to the first issue the tweet mentioned.

$x$ The coding of some tweets about Brexit, particularly by the Conservative party, posed a distinctive challenge. A typical example is this tweet posted by Theresa May's account on June, $2^{\text {nd: }}$ "Brexit is an opportunity to shape 
a better, brighter future for the UK. Back me and I'll work every day to make it a success." Here, the choice whether to leave the EU is taken for granted and May presents herself as the right person to implement this choice. This approach, which was very common in Conservatives' communication, could be seen as a treatment of the issue as valence rather than positional. However, we decided to code this and similar tweets as referring to the positional issue of staying in the EU or leaving it, for two reasons. First, substantively, although the choice whether to leave the EU had been made by voters in the 2016 referendum, the population was still as divided on it during the 2017 campaign as it had been during the referendum campaign, and as such Brexit does not meet the crucial valence criterion of entailing a widely agreed-upon goal. Secondly, for this precise reason we measured this issue as a positional rather than a valence issue in our survey, and indeed found the public was still split (with 55\% favouring leaving the EU and 45\% staying in the EU) on this issue-similar to most opinion polls at the time. Since our mixed-methods design combines survey and content analysis data, classifying Brexit-related tweets as positional enabled us to compare voters' priorities and parties' communications on this crucial issue. However, we ran some robustness checks that confirmed that the results presented in this study, and particularly the findings from the multivariate models presented in Table 2 and Figure 3, do not substantively change if we code those Brexit tweets as valence rather than positional-even though this effectively means excluding them from the analyses combining survey and social media data.

xi We classified 307 tweets (8.24\% of our corpus) that mentioned issues not included in our original list, and thus not measured in the voter survey, as focusing on "other issues". A large number of tweets $(1,605$, or $43.08 \%$ of the total) did not mention any issue at all, so we classified them as "non-issue content" and excluded them from subsequent analyses. The tweets classified as "non-issue content" fell into many different categories. A non-exhaustive list includes: calls to action (to donate money, to spread the word, to attend electoral rallies, and to vote), media appearances, live updates on campaign events and candidate visits, promotion of individual candidates, campaign announcements, and jokes.

xii Considering Corbyn's left wing positions on taxes and spending, it may be argued that Labour's position on the NHS, which we classified as a valence issue, was actually a positional choice to invest in the public healthcare provider and to contrast the tendency to privatize some of its services. If that were the case, then our classification of tweets discussing the NHS (and possibly other public services) as addressing a valence issue may be incorrect. To verify the validity of this claim, we went back to our Twitter dataset and recoded all the 81 tweets that Corbyn and Labour posted during the campaign that we had classified as primarily focused on the NHS. Using the same coding rules as for the original analysis, two of the authors independently coded all the tweets to assess whether they presented the issue as positional or valence. After resolving disagreements, we coded 70 tweets (86\%) as valence and $11(14 \%)$ as positional. An example of a tweet coded as valence is: "We're pledging a New Deal for the NHS to take one million people off waiting lists \& fix England's broken A\&Es." An example of a tweet we coded as positional is: "Labour will step in and save the NHS from Tory cuts and privatisation so it can continue to deliver \#ForTheMany".

xiii In the survey, we asked respondents whether an issue should be considered "high priority", "medium priority", or "low priority". We coded these response categories as $1,0.5$, and 0 , respectively, so the percentages reported in this study refer to the number of respondents who thought each issue was high priority, plus half of the respondents who claimed it was medium priority.

xiv Following the terrorist attacks on May $22^{\text {nd }}$ and June $3^{\text {rd }}$, described in the note above, all parties and leaders posted tweets expressing solidarity to the victims and calls for national unity in the face of the attacks. We did not code these tweets as addressing the valence issue of protecting the UK from terrorist attacks, as the messages did not argue that any party or leader was or was not willing or capable to achieve this goal.

xv Issue yield and systemic salience are not highly correlated $(r=.170, p=0.027, N=168)$ and it is, therefore, not a problem to model the two variables simultaneously.

xvi To verify that the distinct cross-cutting dimension of the constitutional question in Scotland did not affect our results, we performed a robustness check of our analyses excluding the SNP from the analyses. The results are presented in Appendix C. The results clearly indicate that excluding the SNP does not affect the result substantially. Issue yield slightly outperforms systemic salience in the analysis excluding the SNP (see the combined model in Table C1), but this is to be expected as the SNP heavily focussed on issues that were salient in the electorate as a whole. 